13

\title{
Сканирующая туннельная микроскопия поверхности нанопленок иттербия и адсорбированных на ней слоев молекул кислорода
}

\author{
() М.В. Кузьмин, М.А. Митцев \\ Физико-технический институт им. А.Ф. Иофрфе РАН, \\ 194021 Санкт-Петербург, Россия \\ e-mail: m.kuzmin@mail.ioffe.ru
}

Поступило в Редакцию 11 марта 2020 г.

В окончательной редакции 11 марта 2020 г.

Принято к публикации 12 марта 2020 г.

С помощью сканирующей туннельной микроскопии впервые исследованы поверхности структур $\mathrm{Yb}-\mathrm{Si}(111)$ и $\mathrm{O}-\mathrm{Yb}-\mathrm{Si}(111)$ (толщина нанопленок иттербия в них составляет 16 монослоев $(6.08 \mathrm{~nm})$ ) и получены сведения о морфологии и фазовом составе этих поверхностей. Установлено, что до адсорбции кислорода нанопленки имеют высокую степень однородности по толщине, растут по механизму, очень близкому к послойном, и имеют однородную кристаллическую структуру. После адсорбции кислорода образуется островковый слой молекул кислорода, высота которого составляет $0.112 \mathrm{~nm}$. Показано, что морфология нанопленки на тех участках ее поверхности, которые покрыты мономолекулярной пленкой кислорода, существенно изменяется. В то же время морфология участков поверхности, незанятых адсорбированным слоем, остается неизменной.

Ключевые слова: нанопленки, адсорбированные молекулы, поверхность, морфология, сканирующая туннельная микроскопия.

DOI: $10.21883 /$ JTF.2020.08.49548.81-20

\section{Введение}

В настоящее время уделяется значительное внимание изучению структур нанометрового размера $[1,2]$. В частности, довольно много работ посвящено изучению адсорбционных свойств таких структур. При этом в значительной части из них в качестве адсорбата используются молекулы кислорода и монооксида углерода [3-8]. Недостатком этих работ является то, что в них не проводилось систематическое изучение типа адсорбционной связи этих молекул с поверхностью нанообъектов, размерных зависимостей адсорбционных свойств последних и возможного влияния адсорбата на свойства их объема.

В отличие от только что указанных работ в исследованиях авторов настоящей работы едва ли не основное внимание уделяется изучению природы адсорбционной связи молекул с поверхностью нанообъектов (пленок нанометровой толщины) и влияния адсорбата на свойства их объема. Так, в работах [9-12] было показано, что молекулы СО при адсорбции на нанопленках иттербия своими двумя неподеленными электронами образуют с поверхностью подложек донорно-акцепторную связь. Было установлено также, что при толщине пленок иттербия от 1 до 16 монослоев (ML) $(0.38-6.08 \mathrm{~nm})$ адсорбция молекул $\mathrm{O}_{2}$ и $\mathrm{CO}$ сопровождается его переходом из двухвалентного (электронная конфигурация $[\mathrm{Xe}] 4 f^{14} 6 s^{2}$, в дальнейшем - $\left.\mathrm{Yb}^{2+}\right)$ в трехвалентное металлическое состояние (конфигурация [Хе $] 4 f^{13} 5 d^{1} 6 s^{2}$, $\left.\mathrm{Yb}^{3+}\right)$. Согласно полученным данным, указанный переход обусловлен кулоновским взаимодействием локализованных на поверхности электронов, формирующих связь молекул с поверхностью, и электронами проводимости иттербия. Результатом этого взаимодействия является перетекание части электронов проводимости из металла в адсорбированные молекулы. Это перетекание сопровождается понижением $5 d$-уровня иттербия ниже уровня Ферми, т.е. переходом из двухвалентного состояния в трехвалентное.

Интерпретация полученных в цитируемых работах результатов была проведена в рамках ряда важных предположений. В частности, предполагалось, что поверхность пленок иттербия имеет малую шероховатость, т.е. пленки весьма однородны по толщине, и что адсорбированные слои молекул $\mathrm{O}_{2}$ и $\mathrm{CO}$ на поверхности растут островками. Однако использованные в ранних исследованиях экспериментальные методы не давали возможности подтвердить или, наоборот, опровергнуть указанные предположения. Целью настоящей работы было получить с помощью известных экспериментальных методов качественно новые результаты, которые, с одной стороны, давали бы возможность количественно охарактеризовать поверхности нанопленок иттербия, на которые наносятся молекулы газов, а с другой стороны, получить данные о морфологии и фазовом составе адсорбированных слоев. Весь этот комплекс результатов в настоящей работе был впервые получен с помощью сканирующей туннельной микроскопии (СТМ).

\section{Методика экспериментов}

Выбор экспериментальных методов, которые позволили бы получить указанные во Введение данные о со- 
стоянии поверхности нанопленок иттербия, определялся следующим. Так как пленки иттербия, создаваемые путем осаждения на поверхность монокристаллического кремния $\operatorname{Si}(111)$ или текстурированных вольфрамовых лент с преимущественным выходом на поверхность грани (100), оказывались неупорядоченными [13], для их характеризации не могли быть использованы такие структурные методы, как дифракция медленных электронов (ДМЭ) и дифракция быстрых электронов (ДБЭ). Кроме того, методами ДМЭ и ДБЭ не могли быть получены надежные данные об однородности толщины нанопленок, являющейся их важнейшим свойством. В настоящей работе для получения таких данных применялся метод СТМ, что в полном соответствии с предположением авторов дало возможность исследовать шероховатость поверхности исследуемых структур и получить информацию о „плоскопараллельности“ используемых в работе нанопленок. Предполагалось также, что кроме указанных выше результатов, СТМ позволит получить данные о структуре и фазовом составе слоя адсорбированных молекул (в качестве адсорбата использовались молекулы кислорода), осаждаемых на поверхность нанопленок иттербия.

Эксперименты проводились in situ в сверхвысоковакуумной системе с базовым давлением ниже $1 \cdot 10^{-10}$ Torr, которая была оборудована сканирующим туннельным микроскопом STM 1 фирмы Omicron GmbH (Германия), работающим при комнатной температуре. Нанопленки иттербия создавались путем напыления металла на подложки из монокристаллического кремния с ориентацией поверхности (111) также при комнатной температуре. Скорость напыления составляла $1 \mathrm{ML} / \mathrm{min}$. За $1 \mathrm{ML}$ была принята величина $7.84 \cdot 10^{14} \mathrm{~cm}^{-2}$, равная концентрации атомов кремния на нереконструированной поверхности $\mathrm{Si}(111)$. Перед напылением металла проводилась серия быстрых нагревов кремниевого образца до $1550 \mathrm{~K}$ для того, чтобы очистить поверхность подложки от чужеродных загрязнений. После очистки на поверхности всегда наблюдалась хорошо упорядоченная реконструкция $(7 \times 7)$, что было подтверждено методами ДМЭ и СТМ. Кроме того, чистота поверхности кремния и нанопленок иттербия контролировалась с помощью рентгеновской фотоэлектронной спектроскопии.

Для получения изображений СТМ был использован режим постоянного туннельного тока (tunneling current, $I_{t}$ ), в котором при выбранном фиксированном значении напряжения смещения, подаваемом на образец относительно иглы (bias voltage, $V_{S}$ ), постоянство величины $I_{t}$ (current setpoint, рабочая точка) в каждой точке изображения поддерживалось за счет изменения расстояния между образцом и острием. В качестве острия использовались тонкие вольфрамовые иглы, которые перед началом экспериментов были приготовлены с помощью электрохимического травления. Для проверки стабильности работы каждого острия использовалась чистая поверхность $\mathrm{Si}(111)$, для которой были получены СТМ изображения реконструкции $(7 \times 7)$ с хорошим атомным разрешением при различных значениях $V_{S}$ и $I_{t}$. Для обработки полученных данных СТМ частично использовался программный пакет WSxM [14].

Адсорбированные слои молекул кислорода на поверхности нанопленок иттербия создавались путем напуска молекулярного кислорода в вакуумную камеру при давлении $2 \cdot 10^{-7}$ Torr и комнатной температуре. Доза напускаемого газа определялась в Лэнгмюрах: $1 \mathrm{~L}=10^{-6}$ Torr $\cdot \mathrm{s}$.

\section{Экспериментальные результаты и их обсуждение}

В предыдущих наших работах было установлено, что адсорбционные свойства нанопленок иттербия, в частности, предельная концентрация адсорбированных на их поверхности молекул, зависят от количества слоев в этих пленках, т.е. их толщины [9]. Было показано, что эта зависимость носит заметный характер при толщинах $\leq 16 \mathrm{ML}$, а для более толстых пленок зависимость выражена значительно слабее. Кроме того, было обнаружено, что электронные свойства нанопленок иттербия, в частности, валентное состояние атомов на их поверхности и в объеме, а также работа выхода существенно, зависят от дозы напускаемого в вакуумную камеру газа. Так, в случае молекулярного кислорода в области малых доз эти изменения носят значительный характер, а при высоких дозах ( $100 \mathrm{~L}$ и выше) они несущественны [15]. Исходя из вышесказанного, в настоящей работе были исследованы структуры $\mathrm{Yb}-\mathrm{Si}(111)$ и $\mathrm{O}-\mathrm{Yb}-\mathrm{Si}(111)$, которые создавались путем напыления на поверхность кремния нанопленок иттербия толщиной $16 \mathrm{ML}$ и адсорбции кислорода дозой $100 \mathrm{~L}$. Отметим, что при данной толщине пленки иттербия могут считаться типичным нанообъектом, для которого проявляется размерная зависимость его свойств, и в то же время можно пренебречь влиянием границы раздела между иттербием и кремниевой подложкой на процессы, происходящие на поверхности пленки, обращенной в вакуум либо контактирующей с адсорбированным слоем молекул кислорода.

В разд. „Введение“ уже отмечалась важность „плоскопараллельности“ нанопленок иттербия в исследовании структур вида „адсорбированный слой молекул нанопленка металла“. Помимо этого, высокая однородность нанопленок иттербия по толщине является необходимым условием наблюдения осцилляций Фриделя в структурах вида „нанопленка металла-кремниевая подложка“", в которых поверхность пленки, обращенная в вакуум, свободна от адсорбированных молекул (более подробно о природе и проявлениях осцилляций Фриделя в таких системах в работе [13]). В настоящей работе вначале мы рассматриваем структуру $\mathrm{Yb}-\mathrm{Si}(111)$, в которой отсутствуют адсорбированные частицы на поверхности нанопленки. На рис. 1 приведено СТМ изображение такой структуры, т.е. поверхности нанопленки иттербия, нанесенной на кремниевый кристалл. Это изображение 


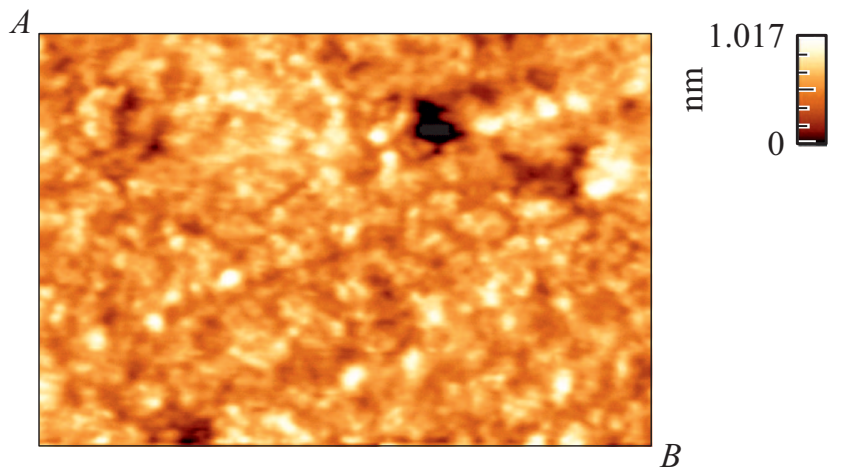

Рис. 1. СТМ изображение поверхности нанопленки иттербия толщиной $16 \mathrm{ML}(6.08 \mathrm{~nm})$, выращенной на кремниевой подложке $\mathrm{Si}(111)$. Напряжение смещения $V_{S}=1.7 \mathrm{~V}$ и туннельный ток $I_{t}=0.06 \mathrm{nA}$. Размер изображения $100 \times 68 \mathrm{~nm}$. В верхней правой части рисунка показана шкала высот $z$ (в $\mathrm{nm}$ ) в градации серого цвета.

было получено при $V_{S}=1.7 \mathrm{~V}$ (при данной полярности напряжения смещения острие „прописывает“ контур постоянной электронной плотности состояний, лежащих выше уровня Ферми образца) и $I_{t}=0.06 \mathrm{nA}$. Размер изображения равен $100 \times 68 \mathrm{~nm}$. На рис. 1 хорошо видно, что поверхность нанопленки является весьма гладкой, без ярко выраженных или регулярно повторяющихся особенностей в виде островков, ступеней и т. п. Отсутствие дальнего порядка на поверхности такой пленки подтверждается результатами метода ДМЭ (не приводятся) и согласуется с выводами более ранних исследований [13].

Другим важным выводом из анализа рис. 1 является наличие на поверхности локальных дефектов в виде глубоких „дыр“ (pinholes), спонтанно образующихся в нанопленке. На изображении СТМ они проявляются в виде темных участков. Существование таких дефектов позволяет объяснить систематически наблюдавшуюся в наших предыдущих работах характерную особенность концентрационных зависимостей оже-сигнала кремния, полученных для структур $\mathrm{Yb}-\mathrm{Si}(111)$ с помощью метода электронной оже-спектроскопии при комнатной температуре. На этих зависимостях сигнал от кремниевой подложки за счет ее экранирования растущей пленкой металла довольно быстро уменьшался с увеличением числа слоев в ней и при толщинах 10-11 ML выходил на „полку“, где практически не зависел от количества металла, но не обращался в нуль даже при очень высоких покрытиях (до $200 \mathrm{ML}$ ). Величина остаточного сигнала кремния при покрытиях металла, больших $10 \mathrm{ML}$, составляла примерно 5\% от величины для чистой подложки. Эти результаты можно объяснить на основании данных СТМ, полученных в настоящей работе. Согласно этим данным, наличие локальных глубоких „дыр“ в пленке металла не позволяет ей полностью экранировать кремниевую подложку даже при очень высоких покрытиях.
Другая важная информация о поверхности исследуемых структур была получена путем количественного анализа СТМ изображений. Кривая 1 рис. 2 представляет собой топографическую профиль-линию $A-B$, взятую на СТМ изображении рис. 1 , т.е. линию, проведенную по совокупности всех точек диагонали $A-B$ этого изображения. В верхней части рис. 2 вертикальная линия показывает масштаб оси, на которой отложена высота $z$. Из анализа вида кривой 1 можно сделать вывод, что максимальная амплитуда изменения высоты на поверхности нанопленки $\Delta z$, т.е. ее пиковая шероховатость, вдоль диагонали $A-B$ составляет $0.821 \mathrm{~nm}$. Длина этой диагонали в плоскости поверхности равна $\sim 120 \mathrm{~nm}$. Типичная же (номинальная или средняя) шероховатость поверхности на участке с характерной длиной $10-20 \mathrm{~nm}$, как видно из рис. 2, составляет в несколько раз меньше $(\sim 0.2-0.3 \mathrm{~nm})$. Если принять, что толщина одного слоя атомов иттербия в пленке равна $0.38 \mathrm{~nm}$, то полученные значения $\Delta z$ составляют соответственно 13.5 и $3.3-4.9 \%$ от полной толщины пленки металла. Ясно, что такая пленка с довольно высокой степенью точности представляет собой „плоскопараллельную“ наносистему, а механизм ее роста близок к послойному.

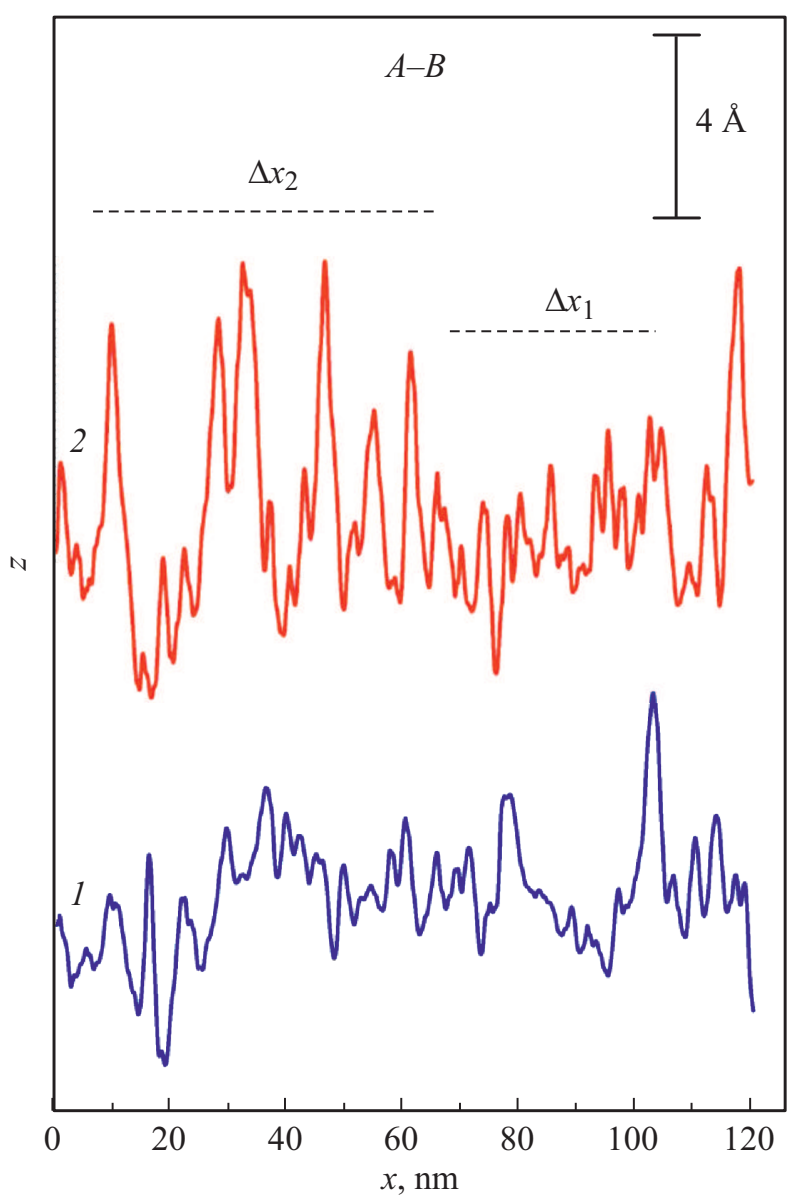

Рис. 2. Профили линии $A-B$ для поверхностей двух структур: $1-\mathrm{Yb}-\mathrm{Si}(111)$ (рис. 1), $2-\mathrm{O}-\mathrm{Yb}-\mathrm{Si}(111)$ (рис. 4). Масштаб по вертикальной оси (высота $z$ ) показан в верхнем правом углу графика. 


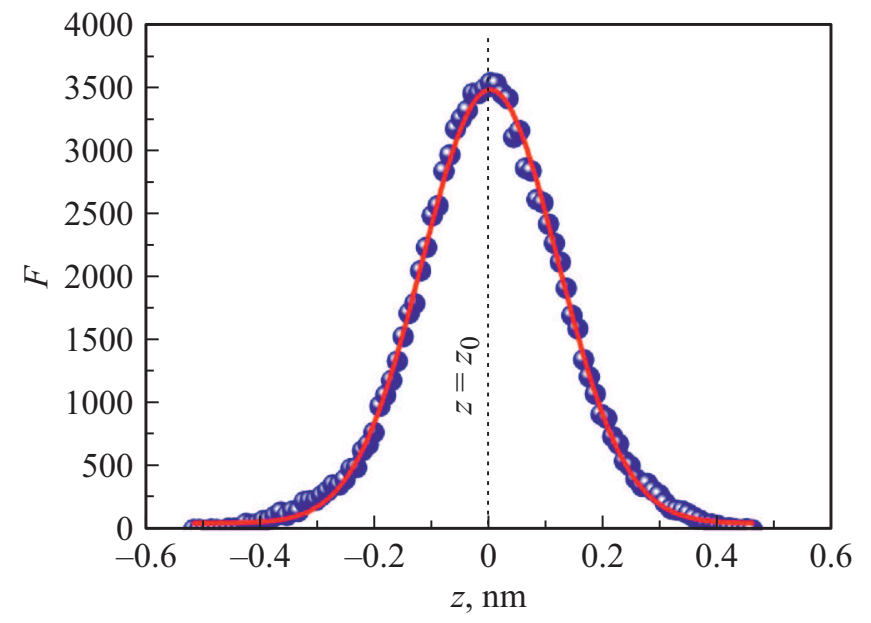

Рис. 3. Гистограмма шероховатости для поверхности $\mathrm{Yb}-\mathrm{Si}(111)$. Использованы данные, приведенные на рис. 1. Экспериментальные точки представлены кружками. Сплошной линией показаны результаты компьютерного моделирования.

В качестве параметра, который характеризует отклонение от идеальной плоскопараллельной системы, можно рассматривать отношение $\Delta z / \Delta x$, где $\Delta z$ - пиковая шероховатость и $\Delta x$ - длина профиля линии. Для случая, показанного на рис. 2, эта величина равна $\Delta z / \Delta x=0.821 \mathrm{~nm} / 120 \mathrm{~nm}=6.8 \cdot 10^{-3}$.

Количественный анализ шероховатости и фазового состава поверхности нанопленок иттербия проводился путем исследования распределения высот на СТМ изображении рис. 1 (гистограммы шероховатости). На рис. 3 в виде кружков представлены экспериментальные данные, каждая точка которых характеризует число повторений $(F)$ высоты на этом изображении в интервале значений от $z-\Delta z$ до $z+\Delta z$, где $\Delta z=4.985 \mathrm{pm}$. Значения $F$ отложены на вертикальной оси. На горизонтальной же оси приведены значения высоты $z$. Очевидно, что чем более шероховатой является поверхность нанопленки, тем шире распределение $F(z)$, и наоборот. В предельном случае, когда пленка имеет идеально гладкую поверхность и высота $z$ на СТМ изображении не зависит от координат в плоскости поверхности, распределение $F(z)$ будет представлять собой единственную точку, значение в которой будет равно количеству точек на СТМ изображении.

Кроме уширения распределения $F(z)$ большой интерес представляет форма его линии. Анализ этой формы может дать сведения о фазовом составе поверхности нанопленки. Так, если поверхность образована двумя различными фазами, например, островками (фаза A) и свободными от них участками гладкой поверхности (фаза $B$ ), то обе фазы дадут вклад в СТМ изображение, и распределение $F(z)$ будет суперпозицией двух распределений, описывающих шероховатость поверхности островков $\left(F_{A}(z)\right)$ и незанятой ими поверхности подложки $\left(F_{B}(z)\right)$, т. е. $F(z)=F_{A}(z)+F_{B}(z)$. Из этого следует, что, раскладывая экспериментально полученную зависимость
$F(z)$ на отдельные компоненты путем компьютерного моделирования (подгонки формы линии), можно получить важные данные не только о степени однородности пленки по высоте, но и ее фазовом составе.

Анализ формы экспериментально полученной для структуры $\mathrm{Yb}-\mathrm{Si}(111)$ зависимости $F(z)$ (кружки на рис. 3) проводился путем компьютерного моделирования с использованием линейной комбинации модельных функций. В качестве модельных функций были протестированы функции разного вида, включая формы Гаусса, Лоренца, Фойгта и т.п. Наилучшие результаты были получены в том случае, когда для подгонки экспериментальных данных использовалась функция Гаусса:

$$
F(z)=\frac{c}{\sigma \sqrt{2 \pi}} \cdot e^{-\frac{\left(z-z_{0}\right)^{2}}{2 \sigma^{2}}},
$$

где $z_{0}$ - математическое ожидание (в контексте настоящей работы - средняя высота поверхностной фазы нанопленки $), \sigma-$ стандартное отклонение $\left(\sigma^{2}-\right.$ среднеквадратичное отклонение, или дисперсия) и $C-$ константа, пропорциональная площади под графиком функции. В случае подгонки распределения $F(z)$, приведенного на рис. 3, для разумного воспроизведения экспериментальных данных была необходима единственная компонента гауссовой формы (она показана сплошной линией на этом рисунке). Введение же дополнительных компонентов не приводило к какому-либо заметному улучшению качества моделирования результатов эксперимента. Как хорошо известно, выражение (1) является нормальным распределением и применяется для описания плотности распределения вероятности случайной величины в случае, когда события слабо зависят друг от друга. Это означает, что распределение высот на поверхности нанопленки иттербия подчиняется нормальному закону и, следовательно, рост пленки металла происходит хаотично (т.е. случайным образом, „внавал“). Скорее всего, такая картина роста пленки связана с тем, что подвижность атомов иттербия недостаточна при комнатной температуре, что препятствует образованию островков и других особенностей морфологии пленки. Наличие единственной компоненты в распределении $F(z)$ свидетельствует об однородности кристаллической структуры нанопленки. Стандартное отклонение, полученное из анализа данных рис. 3 , равно $\sigma=0.118 \mathrm{~nm}$. Шкала $z$ на этом рисунке отложена таким образом, что математическое ожидание $z_{0}=0$.

Аналогичный подход к анализу результатов СТМ был применен и в случае структуры O-Yb-Si(111), полученной путем выдержки нанопленок иттербия в атмосфере молекулярного кислорода. В предшествующих публикациях на основании имеющихся экспериментальных данных было сделано предположение, что диссоциация молекул кислорода на поверхности нанопленки иттербия не происходит [15]. Можно предположить, что в этом случае морфология поверхности образца будет иметь свойства, близкие к свойствам поверхности чистой пленки иттербия. Совсем иная картина будет 


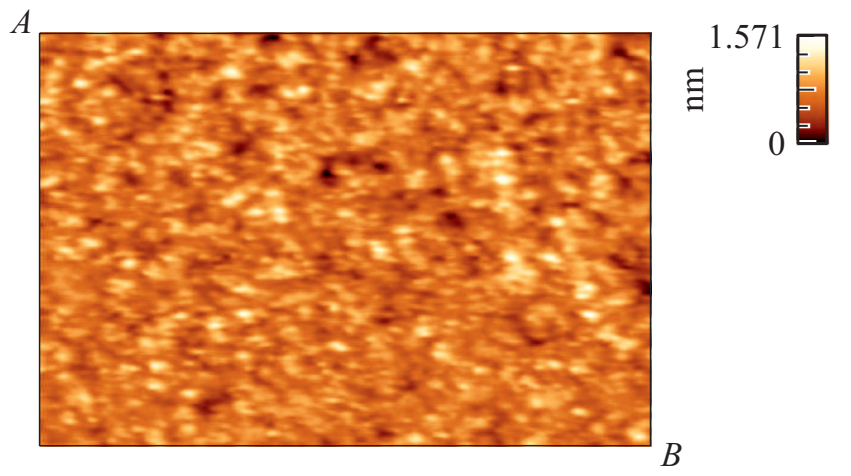

Рис. 4. СТМ изображение поверхности нанопленки иттербия толщиной $16 \mathrm{ML}$ после адсорбции молекул кислорода (доза $100 \mathrm{~L}$ ). Напряжение смещения $V_{S}=1.7 \mathrm{~V}$, туннельный ток $I_{t}=0.06 \mathrm{nA}$. Размер изображения $100 \times 68 \mathrm{~nm}$. В верхней правой части рисунка показана шкала высот $z$ (в $\mathrm{nm})$ в градации серого цвета.

наблюдаться в случае диссоциации молекул: в результате реакции с высвобождающимися атомами кислорода нанопленка иттербия должна трансформироваться в новое состояние $\mathrm{YbO}_{x}$. Морфология и фазовый состав пленок такого соединения, скорее всего, будут существенно отличаться от аналогичных свойств пленок металлического иттербия. Далее в настоящей работе, используя описанный выше подход к анализу результатов СТМ, сделаны попытка прояснить вопрос о возможной диссоциации молекул в системе $\mathrm{O}-\mathrm{Yb}-\mathrm{Si}(111)$ и получить сведения о морфологии и фазовом составе ее поверхности.

На рис. 4 показано СТМ изображение, полученное для поверхности нанопленки иттербия после выдержки ее в атмосфере молекулярного кислорода. Параметры, при которых проводились измерения, были таким же, как при регистрации изображения, приведенного на рис. 1. Из рис. 4 сразу можно сделать вывод, что после выдержки в кислороде морфология поверхности претерпела некоторые изменения, однако они носят в основном количественный, а не качественный характер.

Кривая 2 рис. 2 представляет топографическую профиль-линию, взятую вдоль диагонали $A-B$ СТМ изображения структуры $\mathrm{O}-\mathrm{Yb}-\mathrm{Si}(111)$ на рис. 4. Из сравнения зависимостей 1 и 2 рис. 2 следует, что шероховатость поверхности после адсорбции кислорода возрастает незначительно. Абсолютная величина $\Delta z$ повысилась с $0.821 \mathrm{~nm}$ для чистой нанопленки (кривая 1) до $0.959 \mathrm{~nm}$ для этой же пленки после адсорбции кислорода (кривая 2). Кроме того, видно, что локальная шероховатость вдоль поверхности после адсорбции кислорода неоднородна. Она составляет $\sim 0.2-0.3 \mathrm{~nm}$ на участке $\Delta x_{1}$ и $\sim 0.7-0.8 \mathrm{~nm}$ на участке $\Delta x_{2}$.

Как и в случае чистых нанопленок, более детальную информацию о свойствах поверхности иттербия с адсорбированным на ней кислородом можно получить из анализа распределения высот $F(z)$ на СТМ изображение рис. 4. Эти данные приводятся на рис. 5. Из анализа вида показанной на этом рисунке зависимости $F(z)$ вытекает ряд важных выводов, перечисленных ниже.

Во-первых, гистограмма шероховатости для поверхности после адсорбции кислорода в отличие от аналогичной гистограммы для чистой нанопленки (рис. 3) имеет несимметричный вид. Более сильное уширение наблюдается в области бо́льших значений $z$. Даже без компьютерного анализа очевидно, что наблюдающаяся асимметрия формы линии $F(z)$ связана с появлением дополнительной компоненты, обусловленной адсорбцией кислорода. Количественный анализ показывает, что для удовлетворительной воспроизводимости экспериментальных данных на рис. 5 необходимо использовать линейную комбинацию двух компонент гауссовой формы $\left(F_{1}\right.$ и $\left.F_{2}\right)$. Параметры $z_{01}, \sigma_{1}, C_{1}, z_{02}, \sigma_{2}$ и $C_{2}$, используемые в такой схеме подгонки, были неограниченно варьируемыми переменными. Результаты моделирования представлены на рис. 5. Отдельные компоненты отмечены стрелками и изображены сплошными линиями. Суперпозиция этих компонентов (результат подгонки) также показан сплошной линией, пересекающей кружки (экспериментальные данные). Шкала $\mathrm{z}$ на этом рисунке откалибрована таким образом, что точка $z=0$ совпадает с вершиной распределения $F_{1}\left(z_{01}\right)$. В результате компьютерного моделирования были оптимизированы подгоночные параметры и получены следующие их значения: $z_{02}=0.112 \mathrm{~nm}, \sigma_{1}=0.115 \mathrm{~nm}, \sigma_{2}=0.187 \mathrm{~nm} \mathrm{и}$ $C_{1} / C_{2}=0.364$.

Из представленных выше результатов следует второй важный вывод. Поверхность структуры $\mathrm{O}-\mathrm{Yb}-\mathrm{Si}(111)$ состоит из двух четко выраженных фаз. Фаза, соответствующая компоненте $F_{1}$, имеет стандартное отклонение $\sigma_{1}=0.115 \mathrm{~nm}$. Это значение очень близко к аналогичной величине $(\sigma=0.118 \mathrm{~nm})$ для поверхности нанопленки иттербия до ее выдержки в кислороде (рис. 3). На основании этого можно сделать заключение, что фаза $F_{1}$

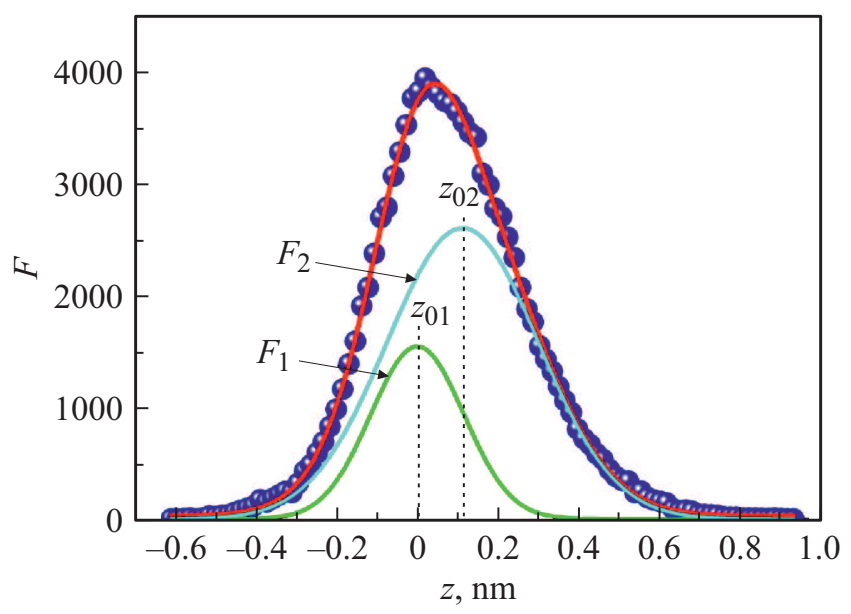

Рис. 5. Гистограмма шероховатости для поверхности $\mathrm{O}-\mathrm{Yb}-\mathrm{Si}(111)$. Использованы данные, приведенные на рис. 4. Экспериментальные точки представлены кружками. Сплошными линиями показаны результаты компьютерного моделирования и разложения зависимости $F(z)$ на отдельные компоненты. 
соответствует чистой, не покрытой кислородом, поверхности иттербия.

Фаза $F_{2}\left(z_{02}=0.112 \mathrm{~nm}\right)$ смещена на шкале высот относительно фазы $F_{1}$ на $1.12 \AA$ в сторону больших значений. На основании этих данных фазу $F_{2}$ можно интерпретировать как участки поверхности нанопленки иттербия, покрытые адсорбированным слоем молекул кислорода. Величина $1.12 \AA$ близка к размеру молекул $\mathrm{O}_{2}$ в газовой фазе. Этот факт дает основание предполагать, что кислород на поверхности иттербия находится в молекулярной форме. Кроме того, указанные данные, по-видимому, означают, что молекулы $\mathrm{O}_{2}$ расположены на поверхности нанопленок иттербия вертикально.

Сосуществование двух компонент $F_{1}$, соответствующей той части поверхности иттербия, которая свободна от адсорбированных молекул $\mathrm{O}_{2}$, и $F_{2}$, формирующейся при выдержке образцов в атмосфере кислорода, означает, что адсорбат сосредоточен в компактных двумерных островках. Последнее, в свою очередь, означает, что между молекулами $\mathrm{O}_{2}$ на поверхности формируются горизонтальные связи. Образование таких связей предполагалось и при интерпретации результатов, полученных при исследовании адсорбции молекул СО на поверхности нанопленок иттербия. Такое исследование было проведено в наших работах [9-12,16]. В этих же работах была рассмотрена возможная физическая природа горизонтальных связей между молекулами СО. При этом учитывая тот экспериментально установленный факт, что при адсорбции достаточно большого количества молекул СО происходит переход части электронов проводимости иттербия в адсорбат, было сделано предположение, что указанные электроны заселяют незаполненные $2 \pi^{*}$ орбитали молекул СО, в результате чего становится возможным формирование горизонтальных связей между последними. Адсорбционные свойства структур $\mathrm{O}-\mathrm{Yb}-\mathrm{Si}(111)$ и $\mathrm{CO}-\mathrm{Yb}-\mathrm{Si}(111)$ очень сходны между собой. На этом основании можно предполагать, что физическая природа горизонтальных связей между адсорбированными на поверхности нанопленок иттербия молекул $\mathrm{O}_{2}$ такая же, как и между молекулами CO. Как уже отмечалось выше, эти связи и обусловливают островковый рост слоев адсорбированных молекул кислорода.

Доля поверхности нанопленки, покрытой адсорбированным слоем молекул $\mathrm{O}_{2}$ на рис. 4 , может быть вычислена из соотношения площадей пиков двух пиков $F_{1}$ и $F_{2}$ на рис. 5. Это отношение равно $C_{1} / C_{2}=0.364$. Иными словами, степень заполнения поверхности островковым мономолекулярным слоем кислорода составляет примерно 3/4 ML. Ясно, что по мере дальнейшего увеличения степени покрытия поверхности нанопленки иттербия таким слоем коэффициент прилипания молекул кислорода из газовой фазы будет быстро убывать, так как будет резко сокращаться доля непокрытой островками поверхности металла. Это будет препятствовать дальнейшему росту мономолекулярного слоя адсорбированных молекул.
Наконец, следует также отметить, что шероховатость при образовании фазы $F_{2}\left(\sigma_{2}=0.187 \mathrm{~nm}\right)$ возрастает примерно на 50-60\% по отношению к шероховатости чистой поверхности иттербия $(0.115-0.118 \mathrm{~nm})$. Это означает, что при взаимодействии с молекулами кислорода происходит реконструкция поверхности иттербия.

\section{Заключение}

Впервые методом СТМ исследованы структуры $\mathrm{Yb}-\mathrm{Si}(111)$ и $\mathrm{O}-\mathrm{Yb}-\mathrm{Si}(111)$, полученные при толщине нанопленок иттербия $16 \mathrm{ML}$ и дозе кислорода $100 \mathrm{~L}$. Показано, что поверхности указанных структур не имеют дальнего порядка. Предложен количественный метод анализа структуры таких поверхностей. Установлено, что поверхность нанопленок иттербия до адсорбции кислорода имеет однородную структуру и низкую степень шероховатости. Средняя неоднородность толщины таких нанопленок составляет $3.3-4.9 \%$, а механизм ее роста очень близок к послойному.

После адсорбции кислорода поверхность образующейся структуры имеет двухфазный характер. Молекулы кислорода образуют двумерные островки, между которыми наблюдаются участки чистой поверхности иттербия. Степень покрытия поверхности иттербия островками мономолекулярного слоя адсорбированного кислорода при дозе $100 \mathrm{~L}$ составляет $\sim 3 / 4 \mathrm{ML}$. Установлено, что высота островков составляет $1.12 \AA$. Эта величина близка к размеру молекул $\mathrm{O}_{2}$ в газовой фазе. Это дает основание предполагать, молекулы ориентированы вертикально относительно поверхности подложки. Обнаружено также, что при формировании островков увеличивается шероховатость поверхности покрытых ими участков нанопленки, что является следствием модификации кристаллической структуры иттербия. Шероховатость же участков нанопленки, незанятых островками, не изменяется.

\section{Конфликт интересов}

Авторы заявляют, что у них нет конфликта интересов.

\section{Список литературы}

[1] Шикин А.М. Формирование, электронная структура и свойства низкоразмерных структур на основе металлов. ВВМ. СПб. 2011. 432 с. ISBN 978-5-9651-0519-9

[2] Cao G., Wang Y. Nanostructures and nanomaterials: synthesis, properties, and applications. World Scientific. 2011. Vol. 2. 581 p. https://doi.org/10.1142/7885

[3] Yang B., Lin X., Gao H.-J., Nilius N., Freund H.-J. // J. Phys. Chem. C. 2010. Vol. 114. N 19. P. 8997-9001. DOI: $10.1021 /$ jp100757y

[4] Zhu L., Zhang L., Virkar A.V. // J. Electrochem. Soc. 2018. Vol. 165. N 3. P. F232-F237. DOI: $10.1149 / 2.0011805$ jes

[5] Qin Z.-H., Lewandowski M., Sun Y.-N., Shaikhutdinov S., Freund H.-J. // J. Phys. Condens. Matter. 2009. Vol. 21. P. 134019 (6p). DOI: 10.1088/0953-8984/21/13/134019 
[6] Wilson E.L., Chen Q., Brown W.A., Thornton G. // J. Phys. Chem. C. 2007. Vol. 111. P. 14215-14222.

[7] Jakob P., Schlapka A. // Surf. Sci. 2007. Vol. 601. P. 3556-3568. https://doi.org/10.1016/j.susc.2007.06.035

[8] Voigts F., Bebensee F., Dahle S., Volgmann K., MausFriedrichs $W$. // Surf. Sci. 2009. Vol. 603. P. 40-49. https://doi.org/10.1016/j.susc.2008.10.016

[9] Кузьмин М.В., Митцев М.А. // ФТТ. 2010. Т. 52. Вып. 3. P. $577-584$.

[10] Бутурович Д.В., Кузьмин М.В., Логинов М.В., Митцев М.А. // ФТТ. 2015. Вып. 57. 9. Р. 1822-1829.

[11] Митцев М.А., Кузьмин М.В., Логинов М.В. // ФТТ. 2016. Т. 58. Вып. 10. Р. 2054- 2058.

[12] Митцев М.А., Кузьмин М.В. // ФТТ. 2018. Т. 60. Вып. 7. P. 1416-1422. DOI: $10.21883 / J T F .2020 .08 .49548 .81-20$

[13] Бутурович Д.В., Кузьмин М.В., Логинов М.В., Митцев М.A. // ФТТ. 2006. Т. 48. Вып. 11. Р. 2085-2088.

[14] Horcas I., Fernández R., Gómez-Rodríguez J.M., Colchero J., Gómez-Herrero J., Baro A.M. // Rev. Sci. Instrum. 2007. Vol. 78. N 1. P. 013705-8. https://doi.org/10.1063/1.2432410

[15] Митцев М.А., Кузьмин М.В. // ФТТ. 2010. Т. 52. Вып. 6. P. $1202-1205$.

[16] Кузьмин М.В., Митцев М.А. // ФТТ. 2014. Т. 56. Вып. 7. P. $1397-1402$. 